\title{
Upcoming conference
}

Traumatic brain injury: models and systems of care

April 11-13, 1996

Key Bridge Marriott, Washington D.C.

Sponsored by: The National Institute on Disability and Rehabilitation Research (NIDRR), US Department of Education and the four Traumatic Brain Injury Model Systems Centers: Medical College of Virginia, Rehabilitation Institute of Michigan, Santa Clara Valley Medical Center, and the Institute for Rehabilitation and Research.

This conference will provide a forum for dis- cussion and dissemination of information among professionals, persons who have sustained traumatic brain injury, and family members. Objectives include providing a description of information gathered through Model Systems Programs as well as encouraging exchange of information and stimulating collaboration among research and clinical centers.

\section{Information:}

Conferencer coordinator:

Jenny Marwitz

Tel: + 1804 8283704; Fax: + 18048282378

Hotel Reservations: +1703524600 or +1800 2289290 